\title{
Política pública de turismo do Amazonas a partir do Modelo de Fluxos Múltiplos
}

Tourism public policy of Amazonas from the Multiple Streams Model La política pública del turismo del Amazonas a partir del Modelo de Múltiples Flujos

http://dx.doi.org/10.18472/vt.16n1.2016.1055

Vânia Lúcia Quadros Nascimento 〈vluciaquadros@yahoo.com.br >

Professora da Faculdade de Turismo da Universidade Federal do Pará (UFPA), Belém, Pará, Brasil.

Ligia Terezinha Lopes Simonian 〈simonianl@gmail.com >

Professora o Programa de Pós-Graduação em Desenvolvimento Sustentável no Trópico Úmido (PPGDSTU) e do Programa de Pós-Graduação em Gestão Pública e Desenvolvimento (PPGGPD) da Universidade Federal do Pará (UFPA), Belém, Pará, Brasil.

Milton Cordeiro Farias Filho 〈mcffarias@gmail.com >

Professor do Programa de Pós-Graduação em Administração da Universidade da Amazônia (UNAMA), Belém, Pará, Brasil.

CRONOLOGIA DO PROCESSO EDITORIAL

Recebimento do artigo: 26-jun-2015

Aceite: 15 -abr-2016

FORMATO PARA CITAÇÃO DESTE ARTIGO

NASCIMENTO, V. L. Q.; SIMONIAN, L. T. L.; FARIAS FILHO, M. C. Política pública de turismo do Amazonas a partir do Modelo de Fluxos Múltiplos. Caderno Virtual de Turismo. Rio de Janeiro, v. 16, n.1, p. 141-157, abr. 2016.

$$
\text { REALIZAÇÃO }
$$

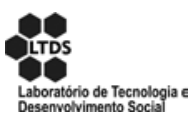

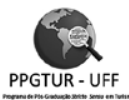

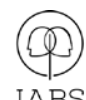

APOIO INSTITUCIONAL

COPPE

UFR]

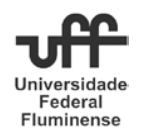

EDIÇÃO

PATROCÍNIO

IR⿴囗十⺝RS

H. 


\section{RESUMO}

Este artigo apresenta os resultados parciais de uma pesquisa sobre a formulação da política pública de turismo. O objetivo foi identificar os fatores e os atores que influenciaram o processo de formulação da política pública de turismo do Estado do Amazonas. Utilizou-se como referencial teórico o Modelo de Fluxos Múltiplos de Kingdon. As evidências estão baseadas em pesquisa documental e entrevistas semiestruturadas com a gestora estadual de turismo. Os resultados apontam que as alternativas para o desenvolvimento do turismo no Estado foram concretizadas no Plano "Victória Régia" e que elas dependeram dos fluxos de problemas, de políticas públicas e da política e da atuação dos participantes ativos. Conclui-se que alguns dos atores listados no Plano não se comportaram do modo como prevê o Modelo utilizado e que as orientações e determinações do Ministério do Turismo brasileiro influenciaram os fluxos de políticas públicas e/ou da política.

Palavras-chave: Políticas públicas. Turismo. Modelo de fluxos múltiplos.

\section{ABSTRACT}

This paper presents partial results of a research about the formulation of the tourism public policy. The objective was to identify the factors and actors that influenced the formulation of the state of Amazonas tourism public policy process. It was used as a theoretical reference of the Multiple Streams Model of Kingdon. The evidences are based on a documentary research and semi-structured interviews with the state manager of tourism. The results indicate that the alternatives for the development of tourism in this state were implemented in the Plan "Victoria Regia" and that they depended on the streams of problems, public policies and politics as well as the performance of active participants. It was concluded that some of the participants listed in the Plan did not behave according to the model used expectancy and that the guidelines and determinations of the Brazilian Ministry of Tourism influenced the streams of public policies and/or politics.

Keywords: Public policy. Tourism. Multiple streams model.

\section{RESUMEN}

Este artículo presenta los resultados parciales de una investigación sobre la formulación de la política pública del turismo. El objetivo fue identificar los factores y actores que influyeron en el proceso de la formulación de la política pública del turismo del estado de Amazonas. Se utilizó como aporte teórico el Modelo de Múltiples Flujos de Kingdon. Las evidencias se sustentan en la investigación documental y en las entrevistas semi-estructuradas con la gestora estatal del turismo. Los resultados indican que las alternativas para el desarrollo del turismo en este estado se han concretado en el Plan "Victória Régia" y que dependieron de los flujos de los problemas, de las políticas públicas y de la política y de la actuación de los participantes activos. Se concluye que algunos de los actores relacionados en el Plan no se comportaron de acuerdo como prevé el Modelo de Múltiples Flujos y que las directrices y determinaciones del Ministerio de Turismo de Brasil influyeron en los flujos de las políticas públicas y de la política.

Palabras clave: Políticas públicas. Turismo. Modelo de múltiples flujos. 


\section{Introdução}

O estabelecimento de uma agenda (agenda setting) ainda é uma fase pouco investigada, em se tratando da análise de políticas públicas de turismo, em especial tomando como base analítica o Modelo de Fluxos Múltiplos (KINGDON, 1995, 2007, 2011). Esse modelo compreende vários processos, abrangendo o estabelecimento de uma agenda e a especificação das alternativas, a partir das quais uma opção autoritária é efetivada. Tais processos estão sujeitos aos participantes ativos e ao procedimento pelo qual alguns assuntos se sobressaem.

Este trabalho trata de uma abordagem da formação de uma agenda de política pública para o turismo. Discute uma das etapas iniciais do processo de formulação das políticas públicas. O que é igualmente incomum, posto que os escassos estudos existentes (p. ex., NASCIMENTO, 2009; SANSOLO, 2013) apreciam as políticas já formuladas ou em execução. Dessa maneira, esta pesquisa partiu do seguinte questionamento: que fatores e atores influenciaram o processo de formulação da política pública de turismo do Estado do Amazonas?

Com vistas de analisar as políticas públicas americanas de saúde e de transportes, Kingdon desenvolveu o Modelo de Fluxos Múltiplos. No Brasil, esse modelo embasou as pesquisas de Capella (2004) e Pinto (2004). A primeira analisou a política de reforma administrativa do ex-presidente Fernando Henrique Cardoso; a segunda, a gestão dos hospitais públicos da Bahia por organizações sociais.

O objetivo da pesquisa aqui apresentada foi identificar os fatores e os atores que influenciaram o processo de formulação da política pública de turismo do Estado do Amazonas. Realizaram-se, para tanto, pesquisa documental e de campo, empregando entrevistas semiestruturadas com a gestora estadual de turismo. Fez-se a pesquisa de campo no órgão gestor de turismo desse Estado.

Os resultados obtidos apontam que as alternativas para o desenvolvimento do turismo, no Amazonas, concretizaram-se no Plano "Victória Régia". Que elas dependeram dos fluxos de problemas, de políticas públicas $^{1}$, da política ${ }^{2}$ e da atuação dos participantes ativos, visíveis e invisíveis. Conclui-se que alguns dos participantes listados no Plano não se comportaram como prevê o modelo utilizado e que um fator distinto aos definidos por ele, as orientações e determinações do Ministério do Turismo brasileiro, influenciou os fluxos de políticas públicas e/ou da política.

\footnotetext{
1 Refere-se, no âmbito desta pesquisa, às propostas para solucionar os problemas, considerando os fluxos do modelo teórico analítico, o Modelo de Fluxos Múltiplos.

2 Diz respeito, baseado no Modelo de Fluxos Múltiplos, ao contexto político no qual as soluções para os problemas são propostas.
} 


\section{A análise das políticas públicas de turismo e o modelo de fluxos múltiplos}

As políticas públicas de turismo têm sido estudadas por pesquisadores de nacionalidades diversas. Eles têm se direcionado para aspectos distintos e analisado as políticas já formuladas e/ou a implementação delas, excetuando-se os autores ingleses que tratam de sua formulação (Quadro 1).

Quadro 1. Estudos internacionais sobre políticas públicas de turismo

\begin{tabular}{|l|l|l|}
\hline \multicolumn{1}{|c|}{ Autor(es)/Ano } & \multicolumn{1}{|c|}{ Aspectos estudados } & \multicolumn{1}{c|}{ Local } \\
\hline $\begin{array}{l}\text { Stevenson, Airey e } \\
\text { Miller (2008) }\end{array}$ & A elaboração da política de turismo em Leeds & Norte da Inglaterra \\
\hline $\begin{array}{l}\text { Farsari, Butler e Szivas } \\
\text { 2011) }\end{array}$ & As políticas de turismo nos quatro níveis decisórios & Grécia \\
\hline Liu, Tzeng e Lee (2012) & $\begin{array}{l}\text { As relações de dependência entre as dimensões e } \\
\text { critérios das políticas de turismo }\end{array}$ & Taiwan \\
\hline $\begin{array}{l}\text { Mei, Arcodia e } \\
\text { Ruhanen (2012) }\end{array}$ & A inovação nas políticas de fomento ao turismo & Noruega \\
\hline $\begin{array}{l}\text { Pastras e Bramwell } \\
\text { (2013) }\end{array}$ & $\begin{array}{l}\text { As continuidades e mudanças da participação } \\
\text { governamental nas políticas de marketing turístico } \\
\text { para Atenas }\end{array}$ & Grécia \\
\hline Wang e Ap (2013) & $\begin{array}{l}\text { Os fatores que afetam a implementação da política de } \\
\text { turismo }\end{array}$ & China \\
\hline Garcia (2014) & A evolução das políticas de turismo & Espanha e Portugal \\
\hline $\begin{array}{l}\text { Rodríguez, Williams e } \\
\text { Hall (2014) }\end{array}$ & A implementação da política de inovação do turismo & Espanha \\
\hline
\end{tabular}

Fonte: Elaborado a partir das obras analisadas

No Brasil, os estudos sobre a análise ou avaliação das políticas públicas de turismo têm sido realizados tendo como objeto, majoritariamente, os Planos Nacionais de Turismo (PNT). E há alguns que versam sobre as políticas voltadas para a Amazônia e, também, as de Estados brasileiros, tais como o Amazonas e o Pará (Quadro 2). Entretanto, em que pese a existência deles, as pesquisas sobre tal temática ainda são escassas, sendo imperativo ressaltar que é possível a existência de outras além das apontadas tanto no Quadro 1 quanto no 2. 
Quadro 2. Síntese dos estudos nacionais sobre a análise de políticas públicas

\begin{tabular}{|c|c|c|}
\hline Autor(es)/Ano & Aspectos estudados & Local \\
\hline $\begin{array}{l}\text { Noia, Vieira Júnior e } \\
\text { Kushano (2007) }\end{array}$ & A estrutura e os impactos do PNT 2003-2007 & Brasil \\
\hline Kanitz et al (2009) & Os conteúdos dos macroprogramas do PNT 2007-2010 & Brasil \\
\hline Sancho e Irving (2010) & $\begin{array}{l}\text { O tema da inclusão social no âmbito do PNT 2003- } \\
2007\end{array}$ & Brasil \\
\hline Sancho e Irving (2011) & O tema da inclusão social no PNT 2007-2010 & Brasil \\
\hline Nascimento (2012) & Análise do relatório de avaliação do PNT 2003-2007 & Brasil \\
\hline Rocha (1997) & Políticas federais de turismo para a Amazônia & Amazônia \\
\hline Sansolo (2013) & $\begin{array}{l}\text { Políticas federais de turismo na Amazônia, } \\
\text { considerando os paradigmas do centralismo e da } \\
\text { descentralização }\end{array}$ & Amazônia \\
\hline Silva (2013) & $\begin{array}{l}\text { Implementação da política estadual que prioriza a } \\
\text { promoção do turismo ecológico e do cultural }\end{array}$ & Amazonas \\
\hline Endres (1999) & $\begin{array}{l}\text { Implementação do Programa Nacional de } \\
\text { Municipalização do Turismo (PNMT) em Belém, } \\
\text { considerando a participação dos atores sociais }\end{array}$ & Pará \\
\hline Cruz (2004) & $\begin{array}{l}\text { O envolvimento das comunidades na implementação } \\
\text { do Proecotur no polo Marajó }\end{array}$ & Pará \\
\hline Hoshino (2007) & $\begin{array}{l}\text { O papel e a participação dos atores sociais na } \\
\text { implementação de políticas de turismo em Soure }\end{array}$ & Pará \\
\hline Nascimento (2009) & $\begin{array}{l}\text { Implementação do Proecotur no polo Belém/Costa } \\
\text { Atlântica }\end{array}$ & Pará \\
\hline $\begin{array}{l}\text { Nascimento e } \\
\text { Simonian (2014) }\end{array}$ & $\begin{array}{l}\text { Implementação da política de ecoturismo no polo } \\
\text { Belém/Costa Atlântica }\end{array}$ & Pará \\
\hline Nascimento (2014a) & $\begin{array}{l}\text { Ascenção do turismo às agendas dos governos dos } \\
\text { Estados do Amazonas e do Pará. }\end{array}$ & Amazonas e Pará \\
\hline Nascimento (2014b) & $\begin{array}{l}\text { As semelhanças e diferenças nas políticas para o } \\
\text { setor de turismo nos Estados do Amazonas e do Pará, } \\
\text { considerando a formulação delas. }\end{array}$ & Amazonas e Pará \\
\hline
\end{tabular}

Fonte: Elaborado a partir das obras analisadas

À exceção dos estudos de Nascimento (2014a, 2014b), ainda em abordagem exploratória, sobre a compreensão do estabelecimento da agenda, os demais analisaram os planos já elaborados e, em geral, em implementação. A construção da agenda e a implementação são algumas das fases do ciclo da política. E a fase de estabelecimento da agenda ou agenda setting esclarece como as agendas dos governos são constituídas e modificadas, sendo esta a que recebe mais atenção.

Kingdon criou o Modelo de Fluxos Múltiplos justamente para estudar essa fase, segundo Theoudolou (1995), Rodrigues (2011) e Silva e Bassi (2012). Para ele, a formulação de políticas públicas abrange processos variados, incluindo o estabelecimento de uma agenda; a especificação das alternativas baseada na qual uma escolha é feita; a escolha entre as alternativas especificadas, via votação no Legislativo ou decisão do presidente; e a implementação dessa decisão (KINGDON, 2011). Ele utiliza seu modelo para analisar os processos pré-decisórios de estabelecimento da agenda e de especificação das alternativas.

Kingdon $(1995,2007,2011)$ faz uma diferenciação entre agenda e alternativas. A primeira é a relação das questões para as quais a atenção de pessoas de dentro e do entorno do governo se volta em dado 
momento. Há, assim, a agenda de governo ou governamental, que congrega as questões para as quais os governantes e seus assessores mais próximos atentam seriamente. E a de decisões ou decisória, que compreende as questões da agenda governamental, efetivamente enviadas para deliberação.

A essa redução do quantitativo de alternativas concebíveis ao que será considerado realmente, esse autor chama de especificação das alternativas. Ele defende que o estabelecimento da agenda e a especificação das alternativas sucedem de maneira diferente. E para compreender como isso ocorre, ele investiga a priorização de algumas questões nas agendas e de outras não; e o motivo de algumas alternativas receberem mais atenção do que outras.

De acordo com Kingdon (1995, 2007, 2011), a explicação para isso tem como foco os participantes, que exercem influência sobre o estabelecimento da agenda e especificação das alternativas e o motivo para isso. E os processos por meio dos quais esses participantes influenciam a agenda e as alternativas. Ele argumenta que existem três fluxos do processo: o dos problemas, o das políticas públicas e o da política; e que os participantes ativos podem ser visíveis ou invisíveis.

Kingdon $(1995,2007,2011)$ define os participantes ativos visíveis como os que recebem atenção considerável da imprensa e do público, tais como o mais alto representante do Executivo e do Legislativo, seus respectivos assessores de alto escalão, a mídia e os atores relacionados ao processo eleitoral (partidos políticos e comitês de campanha). Eles afetam mais o estabelecimento da agenda.

Por outro lado, conceitua como participantes invisíveis os que não recebem atenção da imprensa e do público, a exemplo dos acadêmicos, pesquisadores, consultores, servidores públicos (burocratas) de carreira do Poder Executivo, funcionários do Poder Legislativo, bem como analistas que trabalham para grupos de interesses. Eles atuam em planejamento e avaliação ou em formulações orçamentárias e influenciam mais a especificação das alternativas. Além disso, constituem comunidades de especialistas (em assuntos de certa área em especial), chamadas comunidades de políticas.

Kingdon $(1995,2007,2011)$ defende, ainda, a existência do empreendedor de políticas. Ele investe, quando uma janela para políticas públicas se abre, os recursos de que dispõe (tempo, energia, reputação, dinheiro) na defesa de seu problema ou de suas propostas favoritas, em troca de ganhos futuros. O empreendedor pode ser encontrado entre os participantes visíveis ou entre os invisíveis, sendo responsável, ainda, por conectar os fluxos múltiplos na janela de políticas públicas. É uma pessoa reconhecida por suas conexões políticas, habilidade de negociação e persistência.

Esse autor afirma que os produtos das políticas públicas resultam da convergência de fluxos múltiplos (problemas, políticas públicas e da política), em momentos cruciais, dinamizada pela atuação empreendedora de um empreendedor de políticas. Portanto, soluções se acoplam aos problemas e ambos se unem às forças políticas favoráveis. O que acontece, apenas, quando se dá uma combinação particular de problemas/soluções/participantes/alternativas/escolhas.

De certo modo, os fluxos de problemas, de políticas públicas e da política fluem pelo sistema de maneira autônoma entre si e, cada um deles, de acordo com suas dinâmicas e regras próprias. Mas, quando há a convergência deles, é aberta uma janela para políticas públicas. É a ocasião perfeita para uma questão ser exposta e defendida, soluções apresentadas e essa questão ascender ao topo da agenda de decisões, do governo, gerando alterações nela. Portanto, uma janela para políticas públicas é uma oportunidade de mudança na agenda, via atuação empreendedora de um empreendedor de políticas. 
Conforme Kingdon $(1995,2007,2011)$ argumenta, a dinâmica e as regras dos fluxos de problemas, de políticas públicas e da política são influenciadas por certos fatores. Assim, o fluxo de problemas depende dos indicadores, de eventos-foco e do feedback sobre programas já existentes. A viabilidade técnica, harmonia com os valores da comunidade de especialistas e a antecipação de restrições (restrição orçamentária, aceitabilidade do público e receptividade política) influem sobre o fluxo das políticas públicas. E o fluxo da política está sujeito ao clima ou humor político nacional (estadual ou municipal), às mudanças no interior do governo e às forças políticas organizadas. O que pode ser observado melhor na Figura 1.

Cada um desses fluxos pode atuar como um incentivo ou como uma restrição. Como incentivo, um assunto ocupa lugar de destaque na agenda quando uma administração nova possibilita o surgimento de uma gama de propostas novas. Como restrição, um assunto é impedido de ascender na agenda devido uma restrição orçamentária o excluir por tê-lo como caro, ou por ele não ser aceito pelo público; ou devido ele ser menos premente do que outro na concorrência pela atenção.

Figura 1. Síntese do Modelo de Fluxos Múltiplos de John W. Kingdon

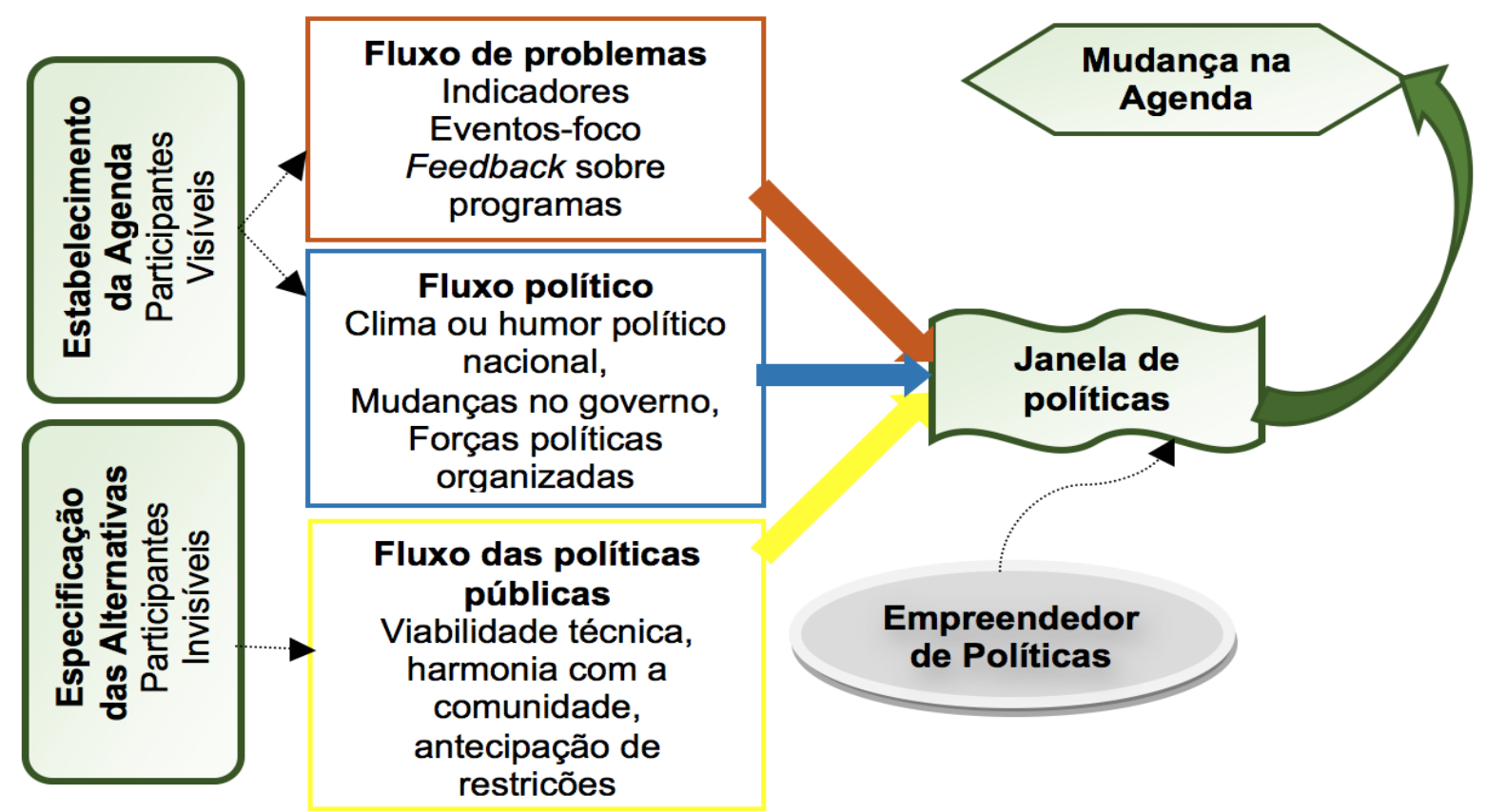

Fonte: Elaborado a partir de Kingdon (1995, 2007, 2011).

Algumas ressalvas são necessárias quanto ao Modelo de Fluxos Múltiplos, mas elas não inviabilizam sua utilização para a análise das fases pré-decisórias da formulação de políticas públicas. De acordo com Capella (2007), o papel das instituições na formulação das políticas públicas foi desconsiderado, de início, por Kingdon, mas ele o fez depois sem, contudo, alterar o modelo. Para Pinto (2008), no entanto, é um modelo pertinente, por permitir analisar os pormenores do processo político nas fases da formulação da política pública, tal como na atuação dos seus participantes. 


\section{Aspectos metodológicos}

A pesquisa ora apresentada foi realizada sob um enfoque interdisciplinar (JANTSCH, 1970), contando com pesquisa documental e de campo. Na documental, utilizou-se a matriz analítica dada por Farias Filho e Arruda Filho (2013). A parte de campo apresenta caráter exploratório, cujos resultados são ainda preliminares.

A pesquisa bibliográfica que alicerça as discussões considerou estudos sobre políticas de turismo e análise de políticas públicas. Isso permitiu encontrar lacunas nas pesquisas na área de turismo e identificar o pouco uso do modelo do ciclo da política e do estabelecimento da agenda.

A pesquisa de campo foi realizada na Empresa Estadual de Turismo do Amazonas (Amazonastur). Foram realizadas, ainda, entrevistas com a gestora de turismo do Amazonas. Os documentos estudados foram o "Plano Estadual de Turismo do Amazonas Victória Régia 2008/2011" e as atas das reuniões dos anos de 2006 a 2008 do Fórum Estadual de Turismo do Amazonas.

A pesquisa documental e as entrevistas semiestruturadas foram efetivadas considerando algumas categorias e variáveis específicas. Elas foram oriundas da obra de Kingdon $(1995,2007,2011)$ e constam de seu Modelo de Fluxos Múltiplos.

As categorias de análise foram: a) problemas (identificação e apresentação); b) políticas públicas (geração, seleção e divulgação das alternativas); c) a política (contexto político e articulação entre os participantes). E as variáveis interpretativas foram: i) para a categoria problemas, os indicadores, os eventos-foco e os feedbacks sobre programas existentes; ii) para as políticas públicas, a viabilidade técnica, a harmonia com os valores das comunidades de especialistas e a antecipação de restrições; iii) para a política, o clima ou humor político estadual, as mudanças no governo e as forças políticas organizadas.

A partir dessas categorias e variáveis, investigaram-se as informações sobre o estabelecimento da agenda e a especificação das alternativas concernentes à política pública de turismo do Estado do Amazonas. Descreveu-se o Plano "Victória Régia", no qual constam as alternativas especificadas. E, por fim, explanou-se sobre os participantes ativos e sobre o processo do qual essas alternativas dependeram.

\section{A política pública de turismo do estado do amazonas}

A política pública de turismo do Estado do Amazonas está consolidada no "Plano Estadual de Turismo do Amazonas Victória Régia 2008/2011" (AMAZONAS, 2008) e foi elaborada pela empresa de consultoria “Indústrias Criativas", no período de 2006 a 2008. O Quadro 3 apresenta uma síntese dessa política. 


\section{Quadro 3 - Síntese da Política Pública de Turismo do Estado do Amazonas}

\begin{tabular}{|c|c|}
\hline Identificação & Caracterização \\
\hline Documento-Base & Plano Estadual de Turismo do Amazonas Victória Régia 2008/2011 \\
\hline $\begin{array}{l}\text { Metodologia } \\
\text { do processo de } \\
\text { formulação }\end{array}$ & $\begin{array}{l}\text { 1) Diagnóstico + análise SWOT, a partir da análise de documentos; da realização } \\
\text { de o3 oficinas em Manaus, Parintins e Tabatinga; da realização de entrevistas } \\
\text { com dirigentes de entidades direta e indiretamente ligadas ao turismo; e de } \\
\text { pesquisa com } 20 \text { empresas de receptivo do Amazonas; } \\
\text { 2) Elaboração de cenários e definição de metas; } \\
\text { 3) Definição dos objetivos estratégicos e da missão do destino; } \\
\text { 4) Formulação das estratégias; } \\
\text { 5) Formulação do plano de ação. }\end{array}$ \\
\hline $\begin{array}{l}\text { Participantes } \\
\text { do processo de } \\
\text { formulação }\end{array}$ & $\begin{array}{l}\text { Três oficinas: representantes do setor público, privado e terceiro setor das } \\
\text { regiões turísticas Manaus/Encontro das Águas (Manaus), Saterê/Tucundeira } \\
\text { (Parintins) e Alto Solimões (Tabatinga), totalizando } 45 \text { pessoas; } \\
\text { Entrevistas: representantes da ABBTUR-AM, ABIH-AM, Abrajet-AM, Abrasel-AM, } \\
\text { Abav-AM, Amazonas Convention \& Visitors Bureau, Associação das Operadores } \\
\text { de Barco de Turismo-AM, Sindicato dos Guias de Turismo do Estado do Amazonas } \\
\text { (Sindegtur-AM), Fundação Nacional do Índio - Administração Executiva Regional } \\
\text { de Manaus, Ibama - Superintendência de Manaus, Secretaria de Meio Ambiente } \\
\text { e Turismo de Tefé/AM, Universidade Federal do Amazonas (UFAM), WWF Brasil - } \\
\text { Escritório de Manaus; } \\
\text { Empresas de receptivos: } 20 \text { representantes (o8 meios de hospedagem, o7 } \\
\text { agências e operadoras de turismo; o3 transportadoras turísticas, o1 agência de } \\
\text { viagem, o1 operadora turística). }\end{array}$ \\
\hline Estrutura do Plano & $\begin{array}{l}\text { Diagnóstico (do turismo no Estado); Cenários para o Turismo (projeção no } \\
\text { Amazonas); Formulação Estratégica (para o alcance do cenário desejado, } \\
\text { incluindo o estabelecimento de objetivos estratégicos e da missão do destino } \\
\text { turístico Amazonas; e os preceitos para o desenvolvimento do turismo no } \\
\text { Amazonas); Metas traçadas para o Plano (o4 metas); Plano de Ação (para } \\
\text { a consecução das metas, sendo um para cada um dos nichos de ação que } \\
\text { configuram o conceito da Victória Régia - Produto, Gestão, Marketing e } \\
\text { Infraestrutura). }\end{array}$ \\
\hline Síntese do Plano & $\begin{array}{l}\text { Quatro metas; } 04 \text { macroprogramas (com base nos } 04 \text { nichos de ação: Produto, } \\
\text { Gestão, Marketing e Infraestrutura), } 09 \text { programas, } 65 \text { ações. }\end{array}$ \\
\hline
\end{tabular}

Fonte: Elaborado a partir de Amazonas (2008).

Com relação às informações sintetizadas no quadro acima, convém traçar algumas considerações. Assim, no que diz respeito aos atores ouvidos nas oficinas, não consta no Plano o quantitativo por categoria ou mesmo por município. E quanto aos entrevistados, o cargo ou função deles também não foi especificado.

De acordo com o descrito no Plano, os turistas foram ouvidos indiretamente, pois as informações referentes a eles foram obtidas por meio de entrevistas com os representantes das empresas de receptivo. E, embora sejam citados indicadores do turismo global e no Brasil, os representantes do trade nacional e internacional, notadamente das agências de viagens, não foram ouvidos.

Cada plano de ação é composto de objetivos estratégicos e de ações a serem implantadas, além das ações já implantadas/programadas pela Amazonastur, para cada objetivo estratégico. Essas ações foram

[...] elaboradas de modo a aproveitar oportunidades e pontos fortes e minimizar pontos fracos e ameaças - ou seja, usar tudo o que existe a favor e trabalhar para diminuir o que há de desfavorável ao Estado (AMAZONAS, 2008, p. 212). 
Percebe-se que elas foram propostas com base no diagnóstico e na análise de SWOT, realizados na fase inicial da metodologia de formulação do Plano, adotada pela consultoria Indústrias Criativas.

Todavia, não foi possível identificar se tais ações integravam as propostas defendidas durante a campanha eleitoral pelo então governador do Estado, e candidato à reeleição, Eduardo Braga. Braga elegeu-se em 2002, para o período de 2003/2006, e foi reeleito em 2006, para o quadriênio 2007/2010. Ressalta-se que o Plano "Victória Régia" teve seu processo de formulação iniciado no final do seu primeiro mandato (2006) e concluído em meados do segundo, sendo lançado em março de 2008.

No período da formulação do Plano "Victória Régia", a Amazonastur respondia pela gestão da atividade turística amazonense, e o faz até hoje, sendo assessorada pelo Fórum Estadual de Turismo do Amazonas. Tal Fórum era e continua sendo composto por representantes da esfera governamental e do trade turístico estadual. A formulação do referido Plano constou da pauta de, ao menos, duas de suas reuniões, abordando a contratação da empresa de consultoria.

Os turistas e a população local não figuram entre os atores visíveis e invisíveis que compõem o Modelo de Fluxos Múltiplos, embora sejam considerados pelos formuladores das políticas públicas de turismo. Porém, eles foram ouvidos pela "Indústrias Criativas", no decorrer da formulação do Plano "Victória Régia", conforme disposto acima. Isso, de modo indireto, como aconteceu com os turistas; e de modo direto, com a população local, durante as oficinas anteriormente apontadas.

Merece destaque a atuação da gestora da Amazonastur no processo de formulação do Plano "Victória Régia”. Ela mantém-se no cargo desde 2003, totalizando 12 anos de gestão do turismo amazonense. Em que pese sua performance ter sido decisiva para a contratação da "Indústrias Criativas", não fica clara sua participação na proposição dos objetivos estratégicos e das ações listados nos Planos de Ação, do referido plano, no entanto, há que reconhecer sua atuação efetiva na posterior divulgação deste.

O panorama acima retrata o processo de formulação da política pública de turismo do Estado do Amazonas e contribui para que, a partir do modelo de análise selecionado, se compreenda a ascensão do turismo na agenda governamental estadual.

\section{A política pública de turismo do amazonas a partir do modelo de fluxos múltiplos}

De acordo com o Modelo de Fluxos Múltiplos, no Plano "Victória Régia" apontam-se os problemas para o desenvolvimento do turismo amazonense, bem como as soluções e alternativas para solucioná-los. Os primeiros estão descritos nas seções que configuram o Diagnóstico, e as soluções e alternativas estão elencadas, majoritariamente, no tópico Plano de Ação. No "Victória Régia" estão, também, enumerados os atores que participaram de sua formulação.

Convém, todavia, destacar duas questões importantes para o entendimento da política pública amazonense de turismo. Tem-se, de início, que a estrutura do Plano "Victória Régia" é análoga à adotada nos Planos Nacionais de Turismo (PNT) 2003-2007 e 2007-2010, pelo Ministério do Turismo (MTUR), congregando um diagnóstico e indicação de alternativas. A diferença é que o "Victória Régia" é detalhado até o nível de ações a serem desenvolvidas, ao passo que nos PNT não há esse detalhamento, restringindo-se ao nível dos macroprogramas e programas. 
A outra questão diz respeito às orientações e determinações do MTUR, a serem seguidas por Estados e municípios. Como exemplo, tem-se os preceitos da regionalização turística estabelecidos pelo Programa de Regionalização do Turismo - Roteiros do Brasil, integrante dos dois PNT. Assim, o planejamento do desenvolvimento do turismo é feito baseado nas regiões turísticas e na formatação de roteiros turísticos integrados, congregando-as.

Em consonância com o Modelo de Fluxos Múltiplos (KINGDON, 1995, 2007, 2011), o estabelecimento da agenda e a especificação das alternativas elencadas no Plano "Victória Régia" estiveram sujeitos aos participantes ativos visíveis e invisíveis e aos processos mediante os quais certos assuntos se sobressaem. Os participantes ativos estão definidos no segundo tópico e elencados no quarto tópico deste artigo. A participação dos atores visíveis e dos invisíveis está descrita a seguir, considerando o estabelecimento da agenda e a especificação das alternativas.

No estabelecimento da agenda destacou-se, como participante visível, o candidato e, em seguida, governador eleito por dois mandatos e sua assessora e nomeada política, a presidente da Amazonastur ( $\mathrm{Fi}$ gura 2). Esta última em razão de sua defesa do turismo como mecanismo de geração de emprego e renda para o Amazonas e da contratação de uma empresa de consultoria para formular o plano estadual de desenvolvimento turístico. Mas, não é possível afirmar que o turismo figurou entre as propostas de campanha do candidato a governador e mesmo a posição adotada por seu comitê de campanha quanto a isso.

Embora tais atores tenham participado do estabelecimento da agenda, nada indica a participação deles na especificação das alternativas constantes no Plano "Victória Régia". No entanto, é inegável que eles atuaram na definição da agenda, porém, consoante ao disposto por Kingdon (1995, 2007, 2011), não da especificação das alternativas. E isso é coerente com o Modelo de Fluxos Múltiplos.

Ainda com base nesse Modelo, pode-se dizer que dois outros atores visíveis tampouco participaram do estabelecimento da agenda. São eles os membros proeminentes da Assembleia Legislativa do Estado do Amazonas (Aleam) e a mídia amazonense especializada ou não. Isso, uma vez que há no Victória Régia indicativo da atuação deles.

Em relação aos participantes ativos invisíveis, conforme o Modelo de Fluxos Múltiplos, constatou-se a atuação de técnicos da própria empresa de consultoria e de funcionários (técnicos) da Amazonastur (Figura 2). Contudo, quem eram os técnicos da Amazonastur, a que escalão da empresa pertenciam e como foi sua participação, não foi possível explicitar. Quanto à consultoria, identificou-se como participante a consultora caracterizada, no corpo do Plano, como coordenadora do projeto Plano "Victória Régia".

Ainda sobre os participantes ativos invisíveis, a atuação dos funcionários do segundo escalão da Aleam não foi constatada, sobretudo dos integrantes da Comissão Técnica Permanente de Turismo e Empreendedorismo. O mesmo ocorreu em relação aos acadêmicos e aos pesquisadores da área de turismo, o que sucede com frequência no processo de formulação de políticas públicas de turismo.

No Plano "Victória Régia" (AMAZONAS, 2008), descreve-se a oitiva de representantes do trade turístico estadual (meios de hospedagem, transportadoras turísticas, agências e operadores de turismo). Relatam-se, também, as informações de representantes dos setores público, privado e do terceiro setor de municípios de três regiões turísticas do Amazonas. E, ainda, de dirigentes de entidades e empresas ligadas direta ou indiretamente ao turismo amazonense, como a ABBTUR-AM, o Amazonas Convention \& Visitors Bureau e a Abrajet-AM. 
Convém destacar que os representantes do trade turístico nacional e internacional não foram ouvidos, e que o Fórum Estadual de Turismo do Amazonas apenas tomou conhecimento da formulação do Plano "Victória Régia", conforme pode ser observado nos relatos abaixo.

\begin{abstract}
[...] tomando a palavra, o Sr. [...], na oportunidade, ressaltou os projetos encaminhados ao Ministério do Turismo e Embratur, direcionados para vários segmentos que compõem a cadeia do Turismo, com aprovação deste Fórum, os quais pretendem ter grande contribuição para o desenvolvimento do turismo no Estado do Amazonas, [...], como: [...] Plano Estadual de Turismo. (Fragmento da Ata da 15a Reunião Ordinária do Fórum Estadual de Turismo do Amazonas, ocorrida em 21/02/2006).
\end{abstract}

[...] a Presidente deste Fórum [...] iniciou sua apresentação [...]. E, em seguida, apresentou as ações relativas ao Departamento de Programas e Projetos, como: [...] 26) Contratação de Consultoria para a Elaboração do Plano Estadual de Turismo do Amazonas; [...]. (Fragmento da Ata da 16a Reunião Ordinária do Fórum Estadual de Turismo do Amazonas, ocorrida em 05/05/2006).

Todavia, nada mais, além disso, foi constatado. Por conseguinte, tem-se que tal Fórum não participou da formulação do Plano "Victória Régia". O que se justifica pelo fato de que não há registro de discussão das propostas e alternativas constantes do Plano ou mesmo da aprovação e/ou validação dele, por parte da plenária do Fórum, nas atas das reuniões dos anos de 2006 a 2008.

O empreendedor de políticas é personificado pela gestora estadual de turismo do Amazonas, que exibe os atributos definidos pelo Modelo de Kingdon (1995, 2007, 2011). Isso, pois, ela preside a Amazonastur, desde sua criação e se coloca em defesa do turismo como ferramenta de promoção de desenvolvimento, geração de emprego e renda e melhoria da qualidade de vida da população amazonense. Ela foi crucial, ainda, na contratação da empresa de consultoria para a elaboração do plano de desenvolvimento turístico do Estado e na presidência das reuniões do Fórum de Turismo, em especial aquelas nas quais a contratação da consultoria foi abordada.

Constata-se, a partir de sua declaração transcrita nas páginas iniciais do Plano "Victória Régia" e das entrevistas, que essa gestora investiu os recursos que possuía (tempo, energia, reputação e financeiros) na defesa do turismo. Em retorno, conseguiu prestígio e o apoio do governador do Estado, consolidado com sua nomeação para a presidência da Amazonastur, conforme abaixo:

O Governador do Estado do AMAZONAS, [...] resolve: NOMEAR, a conta de 09 de maio de 2.003 e nos termos do artigo $7^{\circ}$, II, da Lei $n^{\circ} .1 .762$, de 14 de novembro de 1.986, [...] para exercer o cargo em comissão de Presidente da Empresa Estadual de Turismo - Amazonastur, criado pelo artigo $8^{\circ}$ da Lei $n^{\circ} .2 .797$, de 09 de maio de 2003. (Decreto de 13 de maio de 2003, publicado no Diário Oficial do Estado do Amazonas, nº. 30132, de 13/05/2003).

Ela conseguiu não só o apoio do governador do Estado na época, Eduardo Braga, como também dos que o sucederam, uma vez que ela continua gerindo essa Empresa até os dias atuais. Alcançou, também, projeção e destaque nacional, o que lhe rendeu a eleição à presidência do Fórum Nacional de Secretários e Dirigentes Estaduais de Turismo (Fornatur). Isso pode ser observado a seguir.

\footnotetext{
O Fornatur (Fórum Nacional dos Secretários e Dirigentes Estaduais de Turismo) já tem novos dirigentes. A presidente da Amazonastur (Empresa Oficial de Turismo do Estado), [...], e o secretário de Turismo do Estado do Rio, [...], foram eleitos por aclamação, respectivamente, presidente e vice na manhã da última quarta-feira [30/04/2014], em Brasília, durante a 74a Reunião Ordinária. (NERY, 2014).
}

Vale registrar que o mandato para a presidência do Fornatur é de dois anos, e que a presidente da Amazonastur o presidirá até 2016. 
No que concerne ao fluxo de problemas, observa-se que ele foi influenciado pelos indicadores turísticos apresentados nas seções do Plano "Victória Régia" que compõem o diagnóstico do turismo no Estado. Esses indicadores são, por exemplo: entrada de turistas no Amazonas; distribuição de empreendimentos por tipologia e por região turística; crescimento da oferta de unidades habitacionais; taxa de ocupação média nos hotéis urbanos e de selva; índice de crescimento do fluxo de turistas em cruzeiros marítimos. Tais indicadores serviram para quantificar e qualificar o turismo no Estado.

O Plano "Victória Régia” foi influenciado, ainda, pelo feedback sobre programas já existentes. Isso pode ser verificado no corpo do Plano, pois nele "[...] são expostos alguns dos programas desenvolvidos pela ou que contam com a parceria da Amazonastur" (AMAZONAS, 2008, p. 178). Foram eles: o Programa de Desenvolvimento do Ecoturismo na Amazônia Legal (Proecotur), o Programa de Apoio ao Turismo no Interior do Amazonas (Prointur), o Programa de Pesca e Piscicultura (Propeixe) e o Programa Nacional de Desenvolvimento da Pesca Amadora (PNDPA). A influência de eventos-foco não foi identificada.

Em relação ao fluxo das políticas públicas, notou-se que as alternativas listadas no Plano de Ação integrante do "Victória Régia" foram propostas pela Consultoria, baseadas no diagnóstico e na análise SWOT, considerando a viabilidade técnica. Até o momento não foi possível inferir se elas estavam em harmonia com os valores das comunidades de especialistas, formadas pelos participantes invisíveis antes assinalados; e se foi considerada a antecipação de restrições. Isso, pois, em ambos os casos nada consta no corpo do Plano.

Quanto ao fluxo da política, o clima ou humor político estadual e a mudança no interior do governo do Amazonas, por conta do processo eleitoral, colaboraram para as alternativas. Todavia, a ação das forças políticas organizadas não foi identificada, mas é provável que não tenha sido determinante. Isso, uma vez que há registros, nas atas do Fórum, da presidente da Amazonastur conclamando uma atuação mais efetiva delas, conforme demonstram os relatos a seguir.

[...] a presidente deste Fórum [...]. Ainda com a palavra, ressaltou que o Fórum é um colegiado onde todos podem apresentar projetos para o desenvolvimento do turismo, solicitando mais dinamismo de todos, para não parecer que o turismo é feito exclusivamente pelo Órgão Oficial do Estado. (Fragmento da Ata da $16^{a}$ Reunião Ordinária do Fórum Estadual de Turismo do Amazonas, ocorrida em 05/05/2006).

[...] que o Fórum Estadual de Turismo não é só um fórum para que os membros possam ouvir o que a Amazonastur faz, mas também para opinar e discutir aquilo que cada entidade está fazendo porque quem planeja e desenvolve o turismo no Estado do Amazonas não é o governo, mas é o colegiado que está junto, sobretudo o trade, os parceiros, as academias e cada um tem sua relevância, cada um tem seu papel a ser desenvolvido que deve ser trazido para esse Fórum para discussão. (Fragmento da Ata da 17a Reunião Ordinária do Fórum Estadual de Turismo do Amazonas, ocorrida em 23/06/2006).

Com esses relatos, observa-se que a influência das forças políticas organizadas amazonenses difere, no estabelecimento da agenda e na especificação das alternativas, do que preconiza o Modelo de Fluxos Múltiplos.

As informações anteriormente apresentadas possibilitam caracterizar e entender os processos de estabelecimento da agenda e de especificação das alternativas consolidadas no Plano "Victória Régia". Isso, a partir do Modelo de Fluxos Múltiplos, conforme esquematizado na Figura 2. 
Figura 2 - A formulação do Plano "Ver-o-Pará” a partir do Modelo de Fluxos Múltiplos

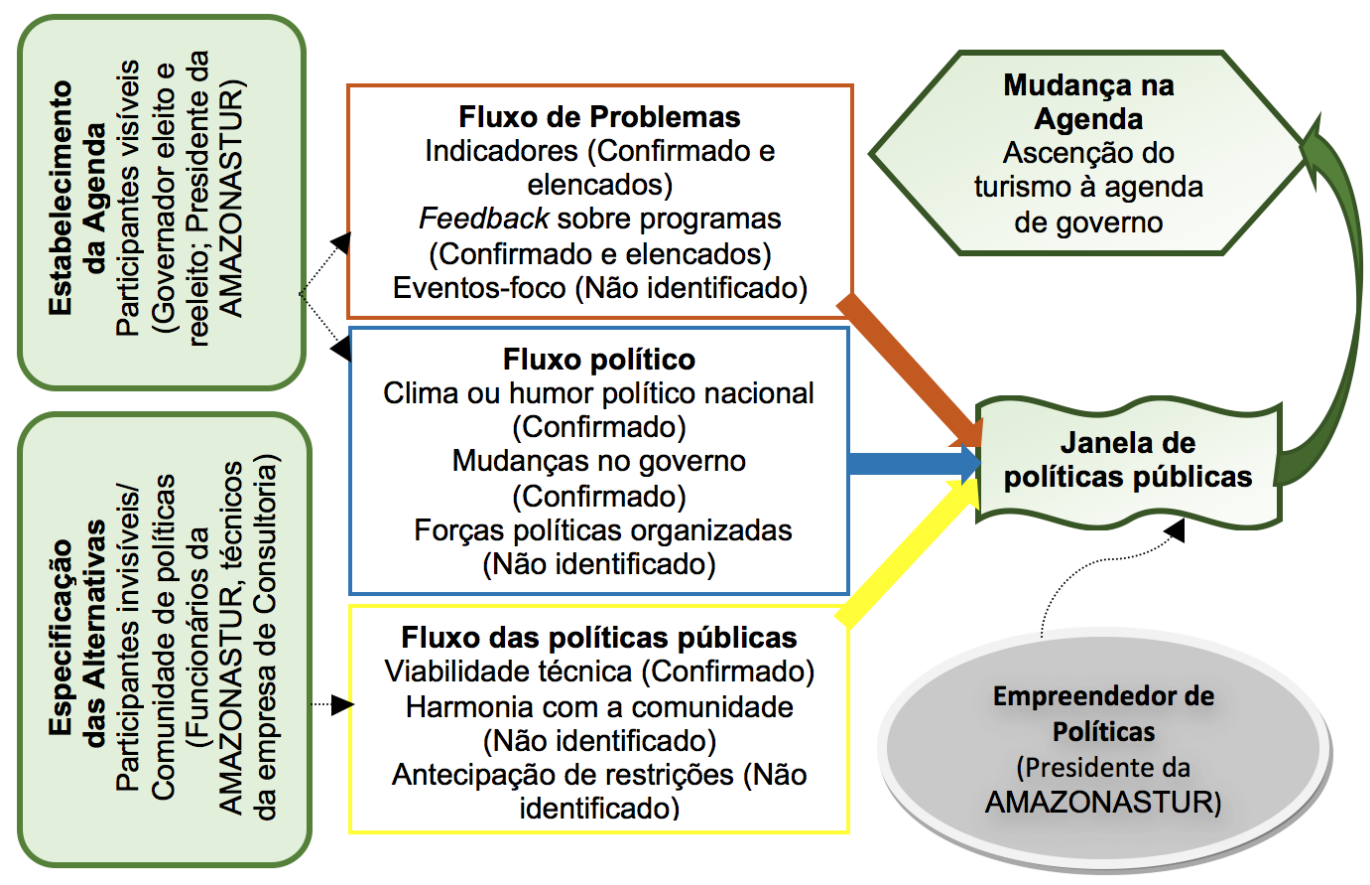

Fonte: Elaborado a partir de Nascimento (2014a; 2014C).

Vale resgatar as orientações e deliberações do MTUR, que não estão entre os fatores que influenciam os fluxos de problemas, de políticas públicas e da política definidos por Kingdon (1995, 2007, 2011). Entretanto, elas são determinantes na atuação da Amazonastur, sendo alguns dos programas, projetos e ações listados no Plano "Victória Régia" influenciados por elas. São exemplos disso as regiões turísticas delimitadas no Estado, os produtos e roteiros turísticos formatados integrando-as e a aprovação, pelo Fórum de Turismo, dos projetos a serem encaminhados ao MTUR.

Por fim, convém refletir sobre a literatura acerca da análise de políticas públicas, descritas no segundo tópico, em especial os estudos de Endres (1999), Cruz (2004) e Hosino (2007). De início, tais estudos são os que mais se aproximam do ora apresentado, pois abordam a atuação dos atores sociais. Todavia, a diferença está no fato de que eles estudam políticas públicas em relação à participação dos atores na implementação delas.

O avanço deste estudo, em relação aos daqueles autores, é que aqui se pode observar a atuação, ou não, dos atores na proposição das políticas públicas. O que pode prepará-los para acompanhar e colaborar melhor e mais efetivamente na implementação das políticas. Pois assim eles saberão como a proposição das ações, projetos e programas ocorreu e, principalmente, o motivo para tanto, mesmo concordando ou não com elas.

\section{Considerações finais}

Esta pesquisa contribui para a análise das políticas públicas de turismo no Brasil e na Amazônia. Isso tomando como base os processos pré-decisórios de estabelecimento da agenda de um governo e da especificação das alternativas para a solução do problema de uma determinada área. Assim, os resultados encontrados evidenciam algumas questões pertinentes. 
As alternativas especificadas dependeram da atuação dos participantes ativos e do processo, constituídos dos fluxos múltiplos, por meio do qual se sobressaíram. Estes, por sua vez, estão consoantes ao que dispõe o Modelo utilizado, quanto à construção da agenda, mas com algumas modificações, que requerem estudos futuros mais pormenorizados.

Em relação aos participantes ativos visíveis e invisíveis, há evidências da participação de alguns, enquanto outros não participaram, isso considerando o que estabelece o Modelo de Fluxos Múltiplos. Logo, quanto à especificação das alternativas, a participação dos atores visíveis Aleam e mídia amazonense sendo esta especializada ou não - é um fator que ainda pode ser examinado melhor.

Foram ouvidos, também, o trade local e os turistas, atores que não constam desse Modelo, mas cujo enquadramento como participantes visíveis ou invisíveis carece de ser determinado. O mesmo ocorre quanto aos representantes dos setores público, privado e do terceiro setor dos municípios das três regiões turísticas amazonenses investigadas e quanto aos das entidades e empresas ligadas direta ou indiretamente ao turismo no Amazonas, de tal modo a caracterizá-los melhor e, consequentemente, examinar sua participação no processo de formulação da política de turismo no Estado.

Os fluxos do processo foram influenciados pelos fatores descritos no Modelo. Todavia, não por todos eles, a exemplo da harmonia com os valores das comunidades de especialistas e da antecipação de restrições no tocante à questão da especificação das alternativas, o que necessita ser estudado melhor. E que a gestora de turismo do Amazonas possui as qualidades que caracterizam o empreendedor de políticas.

O processo de estabelecimento da agenda e de especificação das alternativas da política de turismo do Amazonas aconteceu consonante ao Modelo analítico adotado. Contudo, além da participação de outros atores distintos dos integrantes do Modelo, as orientações e deliberações do Ministério do Turismo também interferem nos fluxos de políticas públicas e/ou da política, uma vez que as gestões estaduais precisam atendê-las em suas políticas públicas de turismo.

Logo, a interferência da gestão federal do turismo sobre a estadual necessita, também, ser objeto de estudo pormenorizado. Isso, de modo a caracterizá-la como fator determinante do fluxo das políticas públicas ou da política ou, até mesmo, dos dois. A continuidade desta pesquisa poderá revelar outros fatores resultantes ou associados a essa interferência.

Por fim, é imprescindível estudar a origem das políticas públicas, para qualquer área, a exemplo do turismo, notadamente a etapa de formulação destas, de modo a compreender os problemas existentes e, não raro, de solução complicada, oriundos de equívocos no momento de sua formulação.

Convém, então, continuar a pesquisa visando discutir essas e as demais lacunas acima apontadas. E, posteriormente, compreender as fases iniciais da formulação das políticas de turismo na Amazônia e a influência delas nos resultados obtidos por essas políticas.

\section{Referências}

AMAZONAS. Empresa Estadual de Turismo. Plano Estadual de Turismo do Amazonas Victória Régia 2008-2011. Manaus: AMAZONASTUR, 2008.

CAPELLA, A. C. N. 0 processo de agenda setting na reforma da administração pública (1995-2002). São Carlos, 2004. 245f. Tese (Doutorado em Ciências Sociais) - Universidade Federal de São Carlos, 2004. 
. Perspectivas teóricas sobre o processo de formulação de políticas públicas. In: HOCHMAN, G.; ARRETCHE, M.; MARQUES, E. (Org.). Políticas públicas no Brasil. Rio de Janeiro: FIOCRUZ, 2007. p. 87-122.

CRUZ, S. H. R. Ecoturismo e desenvolvimento: análise do Programa Nacional de Desenvolvimento do Ecoturismo - Proecotur no polo Marajó/PA. [2004]. Disponível em: 〈http://www.artigocientifico.com. br/uploads/artc_1158893946_78.doc>. Acesso em: 19 jun. 2013.

ENDRES, A. V. As mudanças na condução política do Estado e seus reflexos nas políticas públicas de turismo: em análise o Programa Nacional de Municipalização do Turismo. Belém, 1999. 133f. Dissertação (Mestrado em Planejamento do Desenvolvimento) - Universidade Federal do Pará, 1999.

FARIAS FILHO, M. C.; ARRUDA FILHO, E. J. M. Planejamento da pesquisa científica. São Paulo: Atlas, 2013.

FARSARI, I.; BUTLER, R. W.; SZIVAS, E. Complexity in tourism policies: a Cognitive Mapping Approach. Annals of Tourism Research, [s. l.], v. 38, n. 3, p. 1110-1134, jul. 2011.

GARCIA, F. A. A comparative study of the evolution of tourism policy in Spain and Portugal. Tourism Management Perspectives, [s. l.], v. 11, p. 34-50, jul. 2014.

HOSHINO, Y. Políticas públicas e participação em programas de turismo no município de Soure, PA análise de política. Belém, 2007. 136f. Dissertação (Mestrado em Planejamento do Desenvolvimento) - Universidade Federal do Pará, 2007.

JANTSCH, E. Inter and transdisciplinary university: a systems approach to education and innovation. Policy Sciences, v. 1, n. 1, p. 403-428, 1970.

KANITZ, H. G. et al. Plano Nacional de Turismo 2007/2010: da análise do conteúdo aos desafios da prática. In: SEMINÁRIO DA ASSOCIAÇÃO BRASILEIRA DE PESQUISA E PÓS-GRADUAÇÃO EM TURISMO (ANPTUR), 6, 2009, São Paulo. Anais... São Paulo, 2009. p. 1-12.

KINGDON, J. W. Agenda setting. In: THEODOULOU, S. Z.; CAHN, M. A. (Org.). Public policy: the essential readings. New Jersey, USA: Prentice Hall, 1995. p. 105-113.

-_. Juntando as coisas. In: SARAIVA, E.; FERRAREZI, E. (Org.). Políticas públicas: coletânea. v. 1. Brasília: ENAP, 2007. p. 225-246.

Agendas, alternatives, and public policies. 2th. ed. updated. [S.I.]: Longman Classics, 2011.

LIU, C.-H.; TZENG, G.-H.; LEE, M.-H. Improving tourism policy implementation - the use of hybrid MCDM models. Tourism Management, [s. I.], v. 33, n. 2, p. 413-426, abr. 2012.

MEI, X. Y.; ARCODIA, C.; RUHANEN, L. Towards tourism innovation: a critical review of public polices at the national level. Tourism Management Perspectives, v. 4, p. 92-105, out. 2012.

NASCIMENTO, V. L. Q. Políticas públicas de ecoturismo e participação: a trajetória do Proecotur no polo Belém/Costa Atlântica. Belém, 2009. 212f. Dissertação (Mestrado em Planejamento do Desenvolvimento) - Universidade Federal do Pará, 2009.

. Plano Nacional de Turismo 2003-2007: afinal, o que resultou? In: ENCONTRO NACIONAL DA ASSOCIAÇÃO NACIONAL DE PÓS-GRADUAÇÃO E PESQUISA EM AMBIENTE E SOCIEDADE (ANPPAS), 6, 2012, Belém. Anais... Belém, 2012. v. 1, p. 1-18.

Políticas Públicas de turismo na Amazônia brasileira: o estabelecimento das agendas governamentais do Amazonas e do Pará. Belém, 2014. 231f. Projeto de Tese (Doutorado em Desenvolvimento Sustentável do Trópico Úmido) - Universidade Federal do Pará, 2014a. 
Semelhanças e diferenças das políticas de turismo em estados da Amazônia brasileira. Revista TURyDES - Turismo y Desarrollo Local, v. 7, n. 17, p. 1-11, dez. 2014 b.

NASCIMENTO, V. L. Q.; SIMONIAN, L. T. L. A política de ecoturismo no Polo Belém/Costa Atlântica (PA). Revista Brasileira de Ecoturismo, v. 7, n. 3, p. 618-645, ago./out. $2014 \mathrm{C}$.

NERY, S. Fórum de Secretários de Turismo tem novos dirigentes. Brasília, 2014. Disponível em: 〈http://manchetedahora.blogspot.com.br/2014/05/forum-de-secretarios-de-turismo-tem.html〉. Acesso em: 04 jun. 2015.

NOIA, A. C.; VIEIRA JÚNIOR, A.; KUSHANO, E. S. Avaliação do Plano Nacional de Turismo: a gestão do Governo Lula, entre os anos de 2003 a 2007. CULTUR - Revista de Cultura e Turismo, v. 1, [edição especial], p. 23-38, out. 2007.

PASTRAS, P.; BRAMWELL, B. A Strategic-Relational Approach to tourism policy. Annals of Tourism Research, [s. l.], v. 43, p. 390-414, out. 2013.

PINTO, I. C. de M. Ascensão e queda de uma questão na agenda governamental: o caso das organizações sociais da saúde na Bahia. Salvador, 2004. 238f. Tese (Doutorado em Administração) Universidade Federal da Bahia, 2004.

Mudanças nas políticas públicas: a perspectiva do ciclo de políticas. Revista de Políticas Públicas, São Luís, v. 12, n. 1, p. 27-36, jan./jun. 2008.

ROCHA, G. O. R. da. Ecoturismo na Amazônia: uma análise das políticas públicas planejadas pela Sudam. In: RODRIGUES, A. B. (Org.). Turismo e ambiente: reflexões e propostas. São Paulo: HUCITEC, 1997. p. 161-177.

RODRIGUES, M. M. A. Políticas públicas. São Paulo: Publifolha, 2011. (Folha Explica).

RODRÍGUEZ, I.; WILLIAMS, A. M.; HALL, C. M. Tourism innovation policy: implementation and outcomes. Annals of Tourism Research, [s. l.], v. 49, p. 76-93, nov. 2014.

SANCHO, A.; IRVING, M. Interpretando o Plano Nacional de Turismo 2003/2007 sob a ótica da inclusão social. Caderno Virtual de Turismo, Rio de Janeiro, v. 10, n. 3, 2010.

Tendências de inclusão social no Plano Nacional de Turismo 2007/2012: uma interpretação preliminar. Geografias Artigos Científicos, Belo Horizonte, v. 7, n. 1, p. 44-57, jan./jun. 2011.

$\neg$ SANSOLO, D. G. Políticas e planejamento do turismo na Amazônia. Caderno Virtual de Turismo. Rio de Janeiro, v. 13, n. 1, p. 105-119, abr. 2013.

SILVA, C. L. da; BASSI, N. S. S. Políticas públicas e desenvolvimento local. Petrópolis, RJ: Vozes, 2012.

SILVA, J. M. da. Política de turismo e representações da Amazônia: o turismo ecológico e cultural no estado do Amazonas. Novos Cadernos NAEA, v. 16, n. 1, Suplemento, p. 317-329, jun. 2013.

STEVENSON, N.; AIREY, D.; MILLER, G. Tourism Policy Making: the policymakers' perspectives. Annals of Tourism Research, [s. l.], v. 35, n. 3, p. 732-750, jul. 2008.

THEODOULOU, S. Z. How public policy is made. In: THEODOULOU, S. Z; CAHN, M. A. (Org.). Public policy: the essential readings. New Jersey: Prentice Hall, 1995. p. 86-96.

WANG, D.; AP, J. Factors affecting tourism policy implementation: a conceptual framework and a case study in China. Tourism Management, [s. I.]. v. 36, p. 221-233, jun. 2013. 